\title{
Adolescent pregnancy outcomes at Queen Elizabeth Central Hospital, Malawi: a cross-sectional study
}

\author{
Tamala Chaura $^{1 *}$, Donnie Mategula ${ }^{1,2}$, Luis Aaron Gadama ${ }^{1}$ \\ 1. Kamuzu University of Health Sciences, Malawi \\ 2. Malawi-Liverpool Wellcome Trust, Kamuzu University of Health Sciences, Malawi
}

*Corresponding Author: Tamala Chaura, Email; drt.chaura@gmail.com

\begin{abstract}
Malawi has a growing population with a high Maternal Mortality Ratio (MMR) of 439 per 100,000 live births to which adolescents contribute $25 \%$. Current data suggests adolescent pregnancies in low resource settings are at an increased risk of both maternal and neonatal morbidity.

Objectives

This study assessed the pregnancy outcomes amongst adolescents while using women from the early adulthood (20 - 24-year-old) and advanced maternal age ( 35 years old and above) groups as reference.

Methods

This was a cross-sectional study, carried out at the Chatinkha maternity (labour) and post-natal wards at QECH, and included all adolescents $(10-19$ years old) and women between 20 - 24 years old (early adulthood) and 35 years old or older (advanced maternal age), presenting in labor, at any gestational age $\geq 28$ weeks or with a birth weight of 1000 grams or above.

Results

The study found the prevalence of adolescent pregnancy to be $20.4 \%(\mathrm{~N}=5035)$ out of all the deliveries during the recruitment period. Sexually transmitted infections were proportionally higher in the adolescent group, with 12\% testing HIV seroreactive and 10\% syphilis seroreactive. Neonatal outcomes of birth asphyxia (3.5\%), low birth weight (5\%), prematurity (4.3\%) and early neonatal death (4.3\%) were not statistically different from the outcomes of the older age groups. The major causes of maternal morbidity were determined to be a high caesarean section rate of $31.9 \%$ and intrapartum diagnosis of urinary tract infection (7.4\%), malaria (7.4\%) and hypertensive disorders $(14.5 \%)$.

Conclusions

Adolescents are a significant proportion of the pregnant population in Malawi. These adolescents are at increased risk of some pregnancy and peripartum complications when compared to women of older age groups. However, our study determined that these outcomes appear to be more likely related to the peripartum care received and not solely specific to maternal age.
\end{abstract}

Keywords: Adolescent, Pregnancy, Malawi, Outcomes, Neonatal, Maternal.

\section{Introduction}

The World Health Organization (WHO) data shows a reduction in maternal mortality of $44 \%$ between the period of 1990 to 2015 globally. However, 99\% of all current maternal deaths occur in the developing world, with more than half occurring in Sub-Saharan Africa ${ }^{1}$. Malawi, with its growing population, approximated to be 17 million in 2018, has a high maternal mortality ratio (MMR) of 439 per 100,000 live births. Of these, $25 \%$ of deaths are in mothers below the age of 20 namely adolescents ${ }^{2}$. Malawi has had a drop in the adolescent fertility rate, from 155 (2006) to 141 births per 1,000 women ages 15-19 (2016) which, however, remains well above the global fertility rate of 44 and the SubSaharan Africa rate of $102^{3}$.

The adolescent period is defined as the transitional period before adulthood and occurring between the ages of 10 to 19 years old4. Suicide and pregnancy related complications are the two leading causes of death in adolescent girls aged 15-19. Pregnancy rates within this group are mostly driven by both low economic status, early marriage and a general lower value in educating females within these communities. In addition, restrictive abortion laws and lack of access to reproductive health services, specifically contraceptives, amongst adolescents, has contributed to an increase in unplanned pregnancies ${ }^{2,4}$.

Unwanted pregnancies can either be terminated through unsafe/illegal abortion or result in childbirth which puts these individuals and their offspring at higher risk of perinatal complications such as pre-eclampsia/eclampsia, pre-term delivery, IUGR, anaemia, caesarean delivery and puerperal sepsis $^{5-8}$. Studies from several countries in the Sub-Saharan Africa region have consistently shown increased rates of low birth weight babies, birth asphyxia and higher caesarean section rates within the adolescent group?

In a prospective population-based study of six low-middle income countries which included Kenya, Zambia, India, Pakistan, Guatemala and Argentina, Althabe et al, determined that adolescents did not show an increased risk of maternal adverse outcomes ${ }^{10}$. They, however, noted that the risk of preterm birth (RR 2.07, 95\% CI 1.59 - 2.70) and low birth weight (RR 1.81, 95\% CI 1.40 - 2.34) were significantly higher in adolescents, particularly if below the age of 15 years. This increased risk was suggested to be a result of the biological immaturity, than with socio-economic factors such as inadequate antenatal or intrapartum care ${ }^{10}$.

Similarly, in a cross-sectional study in Latin America, Conde- 
Agudelo et al, concluded that adolescents aged 15 years or younger had higher risks for maternal death, early neonatal death, and anemia compared to adults ${ }^{11}$. Both young and older adolescents had higher risks for postpartum hemorrhage, endometritis, operative vaginal delivery, episiotomy, low birth weight, preterm delivery, and small-for-gestational-age infants ${ }^{11}$. However, they also noted a surprisingly lower risk for cesarean delivery as well as, third-trimester bleeding, and gestational diabetes ${ }^{11}$.

A subgroup analysis of the Mamachiponde study which ran from March 2014 to December 2015, compared birth outcomes between malnourished adolescents and adults in Malawi. They noted that young adolescents $(<18$ years) delivered infants with lower birth weights, who were shorter (by $0.6 \mathrm{~cm}$, p-value $<0.001$ ) and had a smaller head circumference compared to those born to older adolescents and adults. They concluded that adolescence may lead to a competition for nutrients between the mother and fetus and, therefore, may have contributed to lower birth weights and neonatal stunting observed during the study ${ }^{12}$.

Additionally, multiple studies have noted poorer pregnancy outcomes within the extremes of age. Women aged 35 years or older, advanced maternal age, have been documented in literature to be at greater risk of chronic diseases such as hypertension and diabetes mellitus, with poorer early pregnancy outcomes and at higher risk of intrapartum complication when compared to other women of reproductive age ${ }^{13}$. Therefore, a comparison of the outcomes between adolescents and advanced maternal age women would assist in determining the extent of the risk solely attributable to adolescence. Multiple factors may be contributing to the poor adolescent outcomes observed during the adolescent period.

Current literature, however, remains conflicted on whether the adverse outcomes can be solely attributed to nutritional/biological demands of adolescence or whether socioeconomics, and therefore the perinatal care received, plays a more significant role ${ }^{5,10}$.

This study aimed to assess the pregnancy outcomes amongst adolescents presenting at our tertiary hospital while using women from the early adulthood (20 - 24 year old) and advanced maternal age ( 35 years old and above) groups as reference groups.

\section{Methods}

\section{Study place}

This was a cross-sectional study conducted at the Chatinkha maternity (labour) and post-natal wards at Queen Elizabeth Central Hospital (QECH), Malawi. This hospital acts as a tertiary level referral center for the surrounding primary (health center, community and rural hospitals) and secondary (district) level hospitals. The unit manages both high and low risk pregnancies and typically registers over 11,000 deliveries per year.

\section{Study population}

The study population included all adolescents $(10-19$ years old) and women between 20 - 24 years old (early adulthood) and 35 years old or older (advanced maternal age), presenting as an emergency in labor, at any gestational age $\geq 28$ weeks or with a birth weight of 1000 grams or above. Data was collected over a 9 months period starting from 1st September 2018 and ending in May 2019. This timeline included an initial 6 month recruitment period followed by the postpartum follow-up which extended to approximately 3 months.

\section{Study sample size}

We estimated a sample size of 137 adolescents to be recruited in the study to have at least $80 \%$ power to detect an adolescent pregnancy prevalence rate of at least $20 \%$ (with 10\% precision) of all the deliveries at QECH. This $20 \%$ is based on our monthly departmental audits. We did set to recruit more participants to allow multiple subgroup comparisons within the adolescent group and with the older age groups.

\section{Data collection}

All women eligible for inclusion into the study were recruited either during the admission into the labour and postnatal wards, or prior to discharge from the hospital. Data was collected from participants' health passport, files and verbal disclosures, and the patients' intrapartum outcomes were documented as they occurred. Additional data was sought from labour ward registers and intrapartum testing for syphilis, HIV, malaria and anemia was done routinely for all study participants. All mothers and babies were further followed up in both the post-natal ward and nursery, and received a postnatal checkup date for day 7 post-delivery, before discharge home.

The women and babies from all groups were additionally contacted 42 days post-delivery via telephonic communication. The data of those participants we were unable to contact was not included in the final analysis.

\section{Analysis of Data}

Raw data was then analysed using IBM SPSS statistics 20 and Stata. Descriptive analysis was performed to understand the characteristics of the adolescents and their outcomes. Risk ratios were calculated to compare adolescents against the older age groups with confidence intervals of $95 \%$, making a $\mathrm{p}$-value $<0.05$ statistically significant. Data was then illustrated as tables and bar charts.

\section{Ethical considerations}

Ethics approval was sought and granted prior to data collection from the College of Medicine Research Committee (COMREC number P./08/18/2451). In this study, no changes to standard care were made and all patients were managed according to the Obstetrics and Gynaecology guidelines of Malawi as printed in the local handbook14. The research team provided details of the study to all eligible subjects and attempted to answer all questions relating to the study. Fully informed, signed assent was obtained from each subject as well as their guardian if the participant was below the age of 18 years old, prior to admission into the study. Participants above the age of 18 years old were asked to provide their consent as per the current Laws of Malawi. All participants were also advised of their right to discontinue their participation at any time.

\section{Results}

During the recruitment period, 5035 deliveries occurred within the unit, of which $1026(20.4 \%)$ were adolescent mothers. Of this population, 282 adolescents (ranging 13 19 years old and average age of 17.6 years old) were included into the study, with 324 mothers into the early adulthood group and 128 into the advanced maternal age group making 
Table 1: Demographic characteristics by age group

\begin{tabular}{|c|c|c|c|c|c|}
\hline Factor & $\begin{array}{r}13-19 \text { years } \\
\mathrm{N}=282(\%)\end{array}$ & $\begin{array}{r}20-24 \text { years } \\
\mathrm{N}=324(\%)\end{array}$ & $p$-value & $\begin{array}{l}35+\text { years } \\
\mathrm{N}=128(\%)\end{array}$ & $p$-value \\
\hline \multicolumn{6}{|l|}{ Parity } \\
\hline 0 & $270(95.7)$ & $163(50.3)$ & $<0.0001$ & $3(2.3)$ & $<0.0001$ \\
\hline $1-3$ & $12(4.3)$ & $160(49.4)$ & $<0.0001$ & $54(42.2)$ & $<0.0001$ \\
\hline$>3$ & $0(0)$ & $1(0.3)$ & 0.557 & $71(55.5)$ & $<0.0001$ \\
\hline \multicolumn{6}{|l|}{ ANC Visit } \\
\hline $1-3$ & $150(54.7)$ & $169(54.5)$ & 0.956 & $70(57.4)$ & 0.630 \\
\hline $4+$ & $124(45.3)$ & $141(45.5)$ & 0.956 & $52(42.6)$ & 0.630 \\
\hline \multicolumn{6}{|c|}{$\begin{array}{l}\text { Gestation } 1^{\text {st }} \text { ANC Visit } \\
1^{\text {st }} \text { Trimester }\end{array}$} \\
\hline $2^{\text {nd }}$ Trimester & $21(7.5)$ & $23(7.3)$ & 0.909 & $2(1.6)$ & 0.035 \\
\hline \multirow[t]{2}{*}{$3^{\text {rd }}$ Trimester } & $243(86.8)$ & $273(86.1)$ & 0.812 & $105(84.0)$ & 0.473 \\
\hline & $16(5.7)$ & $21(6.6)$ & 0.646 & $18(14.4)$ & 0.005 \\
\hline \multicolumn{6}{|l|}{ Education } \\
\hline None & $6(2.1)$ & $9(2.8)$ & 0.609 & $9(7.0)$ & 0.021 \\
\hline Primary & $170(60.3)$ & $135(41.7)$ & $<0.0001$ & $71(55.5)$ & 0.370 \\
\hline Secondary & $105(37.2)$ & $151(46.6)$ & 0.021 & $43(33.6)$ & 0.482 \\
\hline Tertiary & $1(0.4)$ & $29(2.8)$ & 0.002 & $5(3.9)$ & 0.028 \\
\hline \multicolumn{6}{|l|}{ HIV status } \\
\hline Non-Reactive & $237(84)$ & $282(87)$ & 0.298 & $116(91)$ & 0.050 \\
\hline Reactive & $34(12)$ & $26(8)$ & 0.133 & $10(8)$ & 0.243 \\
\hline Unknown & $11(4)$ & $16(5)$ & 0.538 & $2(2)$ & 0.230 \\
\hline \multicolumn{6}{|l|}{ VDRL status } \\
\hline Non-Reactive & $248(88)$ & $295(91)$ & 0.217 & $118(92)$ & 0.164 \\
\hline Reactive & $28(10)$ & $29(9)$ & 0.681 & $10(8)$ & 0.497 \\
\hline Unknown & $6(2)$ & $0(0)$ & 0.065 & $0(0)$ & 0.224 \\
\hline
\end{tabular}

a total of $734(14.56 \%$ of total deliveries during the study period) participants.

Table 1 illustrates the demographics of the girls and women recruited into the study while table 2 illustrates the adolescent age breakdown. The majority presented for the 1st ANC visit during the 2nd trimester across all age groups. When compared to the early adult group, we noted that adolescents were $45 \%$ more likely to have a primary level of education during their first pregnancy (RR 1.45; $p<0.0001)$. Adolescents were significantly more likely to be primigravid compared to both early adulthood (RR 1.9; p-value < 0.0001) and advanced maternal age (RR 40.9; p-value $<0.0001)$. Additionally, $84 \%$ of adolescents' were human immunodeficiency virus (HIV) non-reactive, while $12 \%$ were noted to be HIV reactive with the majority on highly active antiretroviral therapy (HAART), and 4\% had their HIV status unknown at time of delivery. When compared to the early adulthood group, adolescents had a 1.6 times higher risk ( $\mathrm{p}$-value $=0.133$ ) of being HIV positive, although this did not reach statistical significance. Although, the proportion of adolescents with a positive syphilis status was noted to be relatively high $(10 \%)$, there was no statistical significance when compared with the older age groups.

\section{Peripartum events}

Mode of delivery within all study groups was predominantly vaginal (Table 3), with adolescents exhibiting a statistically higher rate $(65 \%$; $\mathrm{p}$-value $=0.0123)$, and a caesarean section rate of $31.9 \%(\mathrm{p}$-value $=0.0463)$, which was lower than the early adulthood group. Of these caesarean sections, the most common indications were cephalo-pelvic disproportion, previous caesarean section and fetal distress, as illustrated in Table 4 and Table 5 (Robsons classification). The majority 
Table 2: Adolescent age breakdown $(\mathrm{N}=282)$

\begin{tabular}{|l|l|l|}
\hline$\leq 15$ years & $16-17$ years & $18-19$ years \\
\hline 29 & 77 & 176 \\
\hline
\end{tabular}

Table 3: A proportionate comparison of mode of delivery and fetal outcomes within the study population

\begin{tabular}{|c|c|c|c|c|c|}
\hline Factor & $\begin{array}{r}13-19 \text { years } \\
\mathrm{N}=282(\%)\end{array}$ & $\begin{array}{r}20-24 \text { years } \\
\mathrm{N}=324(\%)\end{array}$ & $p$-value & $\begin{array}{l}35+\text { years } \\
\mathrm{N}=128(\%)\end{array}$ & $p$-value \\
\hline \multicolumn{6}{|l|}{ Mode of delivery } \\
\hline Vertex & $184(65.2)$ & $179(55.2)$ & 0.0123 & $82(64.1)$ & 0.8290 \\
\hline Caesarean section & $90(31.9)$ & $128(39.8)$ & 0.0436 & $42(32.8)$ & 0.8567 \\
\hline Breech & $5(1.8)$ & $9(2.8)$ & 0.4165 & $3(2.3)$ & 0.7351 \\
\hline Forceps & $2(0.7)$ & $5(1.5)$ & 0.3526 & $1(0.8)$ & 0.9124 \\
\hline V/Extraction & $1(0.4)$ & $3(0.9)$ & 0.4512 & $0(0)$ & 0.2822 \\
\hline \multicolumn{6}{|l|}{ Outcome of Baby } \\
\hline Live & $271(96.1)$ & $312(96.3)$ & 0.8978 & $127(99.2)$ & 0.0851 \\
\hline FSB & $5(1.8)$ & $4(1.2)$ & 0.5420 & $0(0)$ & 0.1271 \\
\hline MSB & $6(2.1)$ & $8(2.4)$ & 0.8044 & $1(0.8)$ & 0.3452 \\
\hline \multicolumn{6}{|l|}{5 min Apgar score } \\
\hline \multicolumn{6}{|l|}{$<7$} \\
\hline \multirow[t]{2}{*}{$7+$} & $30(10.6)$ & $34(10.7)$ & 0.9683 & $5(4.1)$ & 0.0296 \\
\hline & $252(89.4)$ & $284(89.3)$ & 0.9683 & $118(95.9)$ & 0.0296 \\
\hline \multicolumn{6}{|l|}{ Birth weight (grams) } \\
\hline \multicolumn{6}{|l|}{$<2500$} \\
\hline $2500-3499$ & $48(17)$ & $41(12.7)$ & 0.1313 & $14(10.9)$ & 0.1200 \\
\hline \multirow[t]{2}{*}{$3500+$} & $192(68.1)$ & $214(66.1)$ & 0.5943 & $81(63.3)$ & 0.3526 \\
\hline & $37(13.4)$ & $54(17.5)$ & 0.1656 & $28(22.8)$ & 0.0172 \\
\hline
\end{tabular}

Table 4: Caesarean section indications within the adolescent group

\begin{tabular}{|l|l|l|l|}
\hline & $\leq 15$ years $(\mathrm{N}=6)$ & $16-17$ years $(\mathrm{N}=19)$ & $18-19$ years $(\mathrm{N}=65)$ \\
\hline Indications $\mathrm{n}(\%)$ & & & \\
\hline $\begin{array}{l}\text { Cephalo-pelvic disproportion/ } \\
\text { Failure to progress }\end{array}$ & $2(33.3)$ & $9(47.4)$ & $28(43.1)$ \\
\hline Previous caesarean section & $2(33.3)$ & $5(26.3)$ & $12(18.5)$ \\
\hline Antepartum hemorrhage & $1(16.7)$ & $1(5.3)$ & $3(4.6)$ \\
\hline Hypertensive disorders & $0(0)$ & $2(10.5)$ & $4(6.1)$ \\
\hline Non-reassuring fetal heart rate & $0(0)$ & $1(5.3)$ & $9(13.8)$ \\
\hline Malpresentation & $0(0)$ & $1(5.3)$ & $5(7.7)$ \\
\hline Elective & $1(16.7)$ & $0(0)$ & $3(4.6)$ \\
\hline
\end{tabular}


Table 5:Robsons classification of caesarean section indications within the adolescent

\begin{tabular}{|c|c|c|c|}
\hline & $\begin{array}{l}\leq 15 \text { years }(\mathrm{N} \\
=6)\end{array}$ & $\begin{array}{l}16-17 \text { years }(\mathrm{N} \\
=19)\end{array}$ & $\begin{array}{l}18-19 \text { years }(\mathrm{N} \\
=65)\end{array}$ \\
\hline 1. Nullipara, singleton cephalic, term, spontaneous labour & $3(33.3)$ & $8(42.1)$ & $31(47.7)$ \\
\hline 2. Nullipara, singleton cephalic, term, induced/ c/section before labour & $1(16.7)$ & $0(0)$ & $3(4.6)$ \\
\hline 3. Multipara, singleton cephalic, term, spontaneous labour & $0(0)$ & $2(10.2)$ & $3(4.6)$ \\
\hline 4. Multipara, singleton cephalic, term, induced/ c/section before labour & $0(0)$ & $0(0)$ & $2(3.1)$ \\
\hline 5. Previous c/section, singleton cephalic, term & $0(0)$ & $5(26.3)$ & $12(18.5)$ \\
\hline 6. Nulliparous breech & $0(0)$ & & $4(7.7)$ \\
\hline 7. Multiparous breech & $0(0)$ & $0(0)$ & $1(1.5)$ \\
\hline 8. Multiple pregnancy & $0(0)$ & & $2(3.1)$ \\
\hline 9. Abnormal lie & $0(0)$ & $1(5.3)$ & $0(0)$ \\
\hline 10. All singleton cephalic, $<=36$ weeks & $2(33.3)$ & $3(15.8)$ & $7(10.8)$ \\
\hline
\end{tabular}

Table 6: Relative risk analysis of maternal morbidity and neonatal outcomes between adolescents and early adulthood mothers

\begin{tabular}{|c|c|c|c|c|c|}
\hline Maternal age & $13-19$ years & $20-24$ years & \multirow[b]{2}{*}{$\begin{array}{l}\text { Risk } \\
\text { Ratio }\end{array}$} & \multirow[b]{2}{*}{$95 \% \mathrm{Cl}$} & \multirow[b]{2}{*}{$p$-value } \\
\hline Maternal morbidity & $\mathrm{N}=282(\%)$ & $\mathrm{N}=324(\%)$ & & & \\
\hline Anaemia & $8(2.8)$ & $7(2.2)$ & 1.15 & $0.710-1.86$ & 0.593 \\
\hline Malaria & $21(7.4)$ & $17(5.2)$ & 1.20 & $0.891-1.622$ & 0.265 \\
\hline Hypertension & $41(14.5)$ & $47(14.5)$ & 1.00 & $0.786-1.275$ & 0.990 \\
\hline UTI & $21(7.4)$ & $10(3.1)$ & 1.49 & $1.151-1.933$ & 0.015 \\
\hline APH & $7(2.5)$ & $12(3.7)$ & 0.786 & $0.433-1.425$ & 0.389 \\
\hline PROM & $10(3.5)$ & $23(7.1)$ & 0.638 & $0.377-1.078$ & 0.054 \\
\hline $\mathrm{PPH}$ & $19(6.7)$ & $19(5.9)$ & 1.08 & $0.776-1.50$ & 0.658 \\
\hline C/Section & $90(31.9)$ & $130(39.5)$ & 0.834 & $0.691-1.006$ & 0.052 \\
\hline Neonatal morbidity & & & & & \\
\hline Birth Asphyxia & $10(3.5)$ & $14(4.3)$ & 0.891 & $0.55-1.44$ & 0.625 \\
\hline Low birth weight & $14(5.0)$ & $15(4.6)$ & 1.039 & $0.705-1.53$ & 0.847 \\
\hline Prematurity & $12(4.3)$ & $6(1.9)$ & 1.45 & $1.04-2.04$ & 0.082 \\
\hline Early NND & $12(4.3)$ & $16(4.9)$ & 0.872 & $0.415-1.79$ & 0.690 \\
\hline
\end{tabular}

of cases where performed as emergency caesarean sections only 4/90 (4.44\%) being elective.

The live birth rate within the adolescent group was $96.1 \%$ compared to $96.3 \%$ amongst the early adulthood group and $99.2 \%$ amongst women with advanced maternal age. There were a total of 24 stillborn babies, with 11 occurring in the adolescent group, 12 in the early adulthood group and 1 from the advanced maternal age group. Fresh stillbirths accounted for $5(1.8 \%)$ of the 11 cases in the adolescent group. There was, however, no statistically significant difference between the age groups with relation to number of live births and stillbirths.
A high proportion of neonates of all age groups were born with 5 minute APGAR scores of 7 or above. Comparison data was created, as illustrated by tables 3 and 4, to assess the risk of maternal and neonatal morbidity associated with adolescent pregnancy. The adolescent perinatal mortality rate was determined to be 81.56 per 1000 total births.

Tables 6 and 7 further show the peripartum conditions most prevalent amongst study participants. We noted an increased risk of presenting with urinary tract infections within adolescents compared to the other age groups. Additionally, hypertensive disorders were a clinically significant burden amongst all age groups with $14.5 \%$ of adolescents developing 
Table 7: Relative risk analysis of maternal morbidity and neonatal outcomes between adolescents and advanced maternal age mothers

\begin{tabular}{|l|c|c|c|c|l|}
\hline & $13-19$ years & $35+$ years & & & \\
\cline { 1 - 3 } Maternal morbidity & $\mathrm{N}=282(\%)$ & $\mathrm{N}=128(\%)$ & Risk Ratio & $95 \% \mathrm{Cl}$ & $\mathrm{p}$-value \\
\hline Anaemia & $8(2.8)$ & $1(0.8)$ & 1.30 & $1.022-1.654$ & 0.188 \\
Malaria & $21(7.4)$ & $6(4.7)$ & 1.14 & $0.924-1.412$ & 0.296 \\
Hypertension & $41(14.5)$ & $19(14.8)$ & 0.992 & $0.823-1.195$ & 0.935 \\
UTI & $21(7.4)$ & $2(1.6)$ & 1.353 & $1.172-1.563$ & 0.016 \\
APH & $7(2.5)$ & $6(4.7)$ & 0.777 & $0.467-1.291$ & 0.237 \\
PROM & $10(3.5)$ & $7(5.5)$ & 0.849 & $0.567-1.271$ & 0.365 \\
PPH & $19(6.7)$ & $9(7.0)$ & 0.985 & $0.757-1.282$ & 0.913 \\
C/Section & $90(31.9)$ & $43(32.8)$ & 0.987 & $0.857-1.136$ & 0.856 \\
\hline Neonatal morbidity & & & & & \\
Birth Asphyxia & $10(3.5)$ & $5(3.9)$ & 0.968 & $0.672-1.393$ & 0.857 \\
Low birth weight & $14(5.0)$ & $9(7.0)$ & 0.878 & $0.629-1.227$ & 0.399 \\
Prematurity & $12(4.3)$ & $4(3.1)$ & 1.094 & $0.818-1.463$ & 0.583 \\
Early NND & $12(4.3)$ & $8(6.3)$ & 0.668 & $0.277-1.573$ & 0.3481 \\
\hline
\end{tabular}

these conditions. There was no evidence of an increased risk of developing anemia $(\mathrm{Hb}<11 \mathrm{~g} / \mathrm{dl})$ or malaria amongst the adolescent group.

A total of $19 / 282(6.7 \%)$ adolescent study participants were diagnosed with postpartum sepsis. Retrospective analysis, revealed 15/19 (78.9\%) had undergone caesarean section with the most common indications being 5/15 (33.3\%) cephalo-pelvic disproportion and 5/15 (33.3\%) fetal distress and $5 / 15(33.3 \%)$ being due to other indications. These adolescents had attended an average of 3.01 antenatal care visits, with $2 / 19(10.5 \%)$ being HIV positive on HAART, while $1 / 19(5.6 \%)$ had an intrapartum diagnosis of PROM.

\section{Discussion}

Queen Elizabeth Central Hospital is located in the southern region of Malawi and acts as a tertiary level referral center for the surrounding primary and secondary level hospitals. The maternity ward registers over 11,000 deliveries per year, and this study suggests a $20.4 \%$ (1026/5035) prevalence in adolescent pregnancy. This prevalence is similar to that recorded in other low resource settings, but significantly increased compared to that of higher income countries ${ }^{15-17}$.

A systematic review and meta-analysis of 52 studies from Africa on adolescent pregnancy, determined an overall prevalence of 19.3\% (95\% CI 16.9 - 21.6) for Sub-Saharan Africa $^{18}$. Adolescent pregnancy rates were noted to be highest in East Africa (21.5\%) and lowest in North Africa $(9.2 \%)^{18}$. The review determined that the main factors associated with adolescent pregnancy included living in a rural setting (OR 2.04), early marriage (OR 20.67), not attending school (OR 2.49) and the lack of information on sexual reproductive health issues (OR 2.88) ${ }^{18}$. In Malawi, the Demographic and Health Survey (2015/2016 MDHS) data approximates that $47 \%$ of girls are married before their 18 th birthday ${ }^{2}$. This data also shows that $30.7 \%$ of girls between 15-19 years who reside in the rural areas, and have already started childbearing, compared to $21 \%$ in the urban areas ${ }^{2}$. These teenagers were also likely to have never received formal education $(54.1 \%)$, or were at primary level $(32.2 \%)$ or secondary level $(18.6 \%)$ of education ${ }^{2}$. However, the majority of adolescents, 170/282 (60.3\%), in this study were at a primary level during their pregnancy and only $6 / 282$ $(2.1 \%)$ had no previous education, while 105/282 (37.2\%) were in secondary school. This may reflect current Malawi government policies providing free primary education to all citizens, although a follow-up of study participants after 1 year would be beneficial in revealing the back-to-school rates within this group. As QECH caters for both rural and urban populations, with the majority of Malawian women being from a rural background (80\%), a high adolescent pregnancy rate should be anticipated in our setting ${ }^{2}$. These factors may help to explain the high prevalence we recorded in this study.

\section{Fetal and neonatal outcomes}

Once adolescents have fallen pregnant, the peripartum care they receive can affect the maternal and neonatal outcomes of that pregnancy. This study showed that the incidence of fresh stillbirth was higher in adolescents at 5/282 (1.8\%), than it was in those in the early adulthood group $4 / 324$ $(1.2 \%)$ or the advanced maternal age group $0 / 128(0 \%)$, and should be considered clinically significant. This incidence may suggest poorer adolescent intrapartum care compared to those of advanced maternal age. However, as the majority of adolescents (95.7\%) were primigravid, while those of advanced maternal age (97.7\%) were multigravid suggesting parity may also have some effect. However, Brabin et al concluded in their study that, proportionally, primiparae and multiparae adolescents had similar outcomes of stillbirth $(1.9 \%$ vs. $1.8 \%)$ and neonatal death (3.8\% vs. $3.7 \%)$, which was higher when compared to their reference group of 2024 year olds ( $0 \%$ stillbirth and $1.9 \%$ neonatal death $)^{19}$. These findings correlate with our study's findings and suggest a need for closer intrapartum management of all adolescents whether primigravid or not.

Other significant neonatal outcomes include a high proportion of low birth weight babies 17\% (48/282) which 
was statistically similar to the older age groups, but higher than that previously reported for the Sub-Saharan region $(8.7 \%)^{10}$. This could have been due to our reliance on dating the pregnancy using the woman's last normal menstrual period (LNMP) or their first recorded fundal height during ANC which was mostly in the 2nd trimester. Both these methods would have given us less accuracy in dating compared to a 1st trimester ultrasound scan. And with most of our adolescents being at primary school level, we suggest their immaturity would have prevented them from knowing their exact LNMP and thus led to an over or underestimation of gestational age. This could also mean that the number of premature babies we recorded during our study, $12 / 282(4.3 \%)$, may have been an underestimation of the true prevalence in our setting.

In addition, the number of babies born with 5 minute Apgar scores $<7$ were recorded as $10.6 \%(30 / 282)$ which was similar to the early adult group $10.7 \%$ (p-value 0.9683 ), but significantly higher than the advanced maternal age group (4.1\%; p-value 0.0296). Of those babies with a neonatal diagnosis of birth asphyxia, 10/282 (3.5\%) were from the adolescent group which was comparable to the proportions in both the early adulthood $(14 / 324 ; 4.3 \%)$ and advanced maternal age $(5 / 128 ; 3.9 \%)$ groups. This data further suggests a need for better intrapartum care for all laboring women in our unit.

The adolescent perinatal mortality was also determined to be 81.56 per 1,000 total births and thus considered higher than that previously reported in the 2015/2016 MDHS (45 deaths per 1,000 total births) ${ }^{2}$. The study's increased rate may be easily explained by the fact that as a referral hospital, QECH, would be expected to manage a higher proportion of complicated adolescent cases, and so would expectedly have higher mortality rates than expected at a primary or secondary level hospital. One could also argue that our study's perinatal mortality rate is a more accurate reflection of Malawi considering that the 2015/2016 MDHS data is acquired via verbal autopsy, and this could lead to the underreporting of poor outcomes².

\section{Maternal outcomes}

During the intrapartum period, the proportion of adolescents diagnosed with malaria $21 / 282(7.4 \%)$ and anemia $8 / 282$ $(2.8 \%)$ was not statistically greater than the older age groups. This may be a reflection of the antenatal administration of intermittent preventive therapy with sulphadoxine/ Pyrimethamine (SP) and Albendazole. However, testing for anemia in all participants proved difficult due to our limited resources, and results may poorly reflect the extent of this condition in our setting. From the 2015/2016 MDHS data, the level of anemia in pregnant women was $45 \%$, and, therefore, much higher than what was recorded by our study ${ }^{2}$. We can, therefore, speculate that more of our study participants were anemic prior to admission.

Although the proportions of adolescents presenting with APH 7/282 (2.5\%) and PPH 19/282 (6.7\%), was not statistically different from the older age groups, the clinical significance cannot be questioned. This is because the adolescent deaths that occurred during this study period were all associated with maternal hemorrhage ( 2 antepartum and 1 postpartum), which remains in the top 4 causes of maternal death in Malawi ${ }^{20}$.

When we looked at the modes of delivery, the adolescent caesarean section rate $(31.9 \%)$ in our setting is significantly higher than in similar African studies ${ }^{17,20}$. Similar studies carried out within health facilities in Cameroon showed lower rates of caesarean section, ranging from $5.1 \%$ to $16.4 \% 0^{6,15}$. In our study, the most common indication for caesarean section was cephalo-pelvic disproportion with normal birth weight babies and this may suggest that the smaller pelvic size in adolescents is a contributing factor in the risk for caesarean section, although this point is refuted by the higher rate of vertex deliveries noted within the adolescent group (65\%). With the high caesarean section rate, we noted an associated high rate of sepsis secondary to endomyometritis leading to a total abdominal hysterectomy. Hysterectomies render the young women infertile. In a culture where childbearing is extremely valued, loss of fertility due to the complication of endomyometritis and the resultant hysterectomies is of concern. The stigma associated with infertility puts the woman at risk of domestic abuse/violence, as well as social isolation and ridicule from their communities ${ }^{21}$. Therefore, further investigation and analysis into the intrapartum events associated with these cases would be beneficial in the development of adequate protocols to reduce the number of septic cases in our unit. This study however did not demonstrate unique adolescent risk factors associated with sepsis, as other well known risk factors such as PROM were nonspecific to the adolescent age group, and data on other factors, such as duration of labour and number of vaginal examinations, was not collected.

These outcomes may not be completely different from other women of reproductive age, in our setting. Based on our data, we can only confidently suggest that adolescence will play a significant clinical factor in the neonatal outcome, the risk of caesarean section and, therefore, subsequent sepsis or hysterectomy in our setting. However, the level of significance may be more likely related to the antenatal and intrapartum care received. This is because the poor outcomes were not solely related to adolescent pregnancies when compared to the older age groups. Previous studies comparing low versus high income settings have also shown differing perinatal outcomes, with poorer outcomes occurring within the lower resource settings $\mathrm{s}^{22,23}$.

\section{Strengths and Limitations}

This study was done with sound methodology and is the first of its kind in our setting, to the best of our knowledge. However, the labour ward in QECH is an extremely busy clinical environment which proved a constraint to recruitment and subsequent follow-up of participants. Most study participants were referral cases from surrounding districts and could only be reached telephonically. Those with limited access to telephonic communication were, therefore, lost to follow-up and their data excluded from analysis.

Additionally, this study was done at a tertiary level facility and results may not be generalizable to primary level facilities that lack the ability for operative interventions and neonatal high dependency care facilities.

\section{Conclusion}

Adolescents are a significant proportion of the pregnant population in Malawi. They are at increased risk of some pregnancy and peripartum complications when compared to women of older age groups. However, our study, just as other studies have demonstrated, suggests that, unless optimal peripartum care is available, poor outcomes cannot 
be solely attributed to age. Resources, both human and material, are required to ensure optimum care during the antenatal, intrapartum and postpartum periods.

\section{Acknowledgements}

The authors would like to thank Mr Malunga for his input during the statistical analysis of the data used in this manuscript.

\section{References}

1. Alkema L, Chou D, Hogan D, Zhang S, Moller AB, Gemmill A, et al. Lancet. (2016). Global, regional, and national levels and trends in maternal mortality between 1990 and 2015, with scenario-based projections to 2030: a systematic analysis by the UN Maternal Mortality Estimation Inter-Agency Group. 387 (10017): 462-74.

2. Malawi Demographic and Health Survey Health Survey 2015-16. (2017)

3. Adolescent fertility rate (births per 1000 women ages 15-19). United Nations Population Division, World Population Prospects. www. worldbank.org

4. The global strategy for women's, children's and adolescents health (2016-2030). (2015) Every Woman Every Child. https://www. everywomaneverychild.org/global-strategy

5. Ganchimeg T, Ota E, Morisaki N, Laopaiboon M et al. (2014). Pregnancy and childbirth outcomes among adolescent mothers: a World Health Organization multi-country study. BJOG 121 Suppl 1:40-8.

6. Njim T and Agbor VN. (2017). Adolescent deliveries in the semiurban Cameroon: prevalence and adverse neonatal outcomes. BMC Res Notes 26;10(1):227

7. Tadesse E and Nigussie S. (2000). Adolescent pregnancies in Addis Ababa. East Afr Med J 77(8):431-4

8. Bwibo NO. (1985). Birth weights of infants of teenage mothers in Nairobi. Acta Paediatr Scand Suppl 319:89-94

9. Gronvik T and Fossgard Sandoy I. (2018). Complications associated with adolescent childbearing in Sub-Saharan Africa: A systematic literature review and meta-analysis. PLoS One 26;13(9):e0204327

10. Althabe F, Moore JL, Gibbons L, Berrueta M, Goudar SS, Chomba E, Derman RJ, Patel A, Saleem S, Pasha O, Esamai F Garces A, et al. (2015). Adverse maternal and perinatal outcomes in adolescent pregnancies: The Global Network's Maternal Newborn Health Registry study. Reprod Health 12 Suppl 2:58

11. Conde-Agudelo A, Belizan JM and Lammers C. (2004). Maternalperinatal morbidity and mortality associated with adolescent pregnancy in Latin America: Cross-sectional study. American Journal of Obstetrics and Gynecology, 192:342-349

12. Friebert A, Callaghan-Gillespie M, Papathakis PC, and Manary MJ. (2017). Adolescent pregnancy and nutrition: a subgroup analysis from the Mamachiponde study in Malawi. DOI: 10.1111/nyas. 13465

13. Carolan M and Frankowska D. (2010). Advanced maternal age and adverse perinatal outcome: A review of the evidence. Midwifery 27(6):793-801

14. Taulo F, Banda M, Bonongwe P, Chak Y, Chang O et al. (2017). Obstetrics and Gynaecology protocols and guidelines. Version 3.0.

15. Tamambang RF, Njim T, Njie AE, Mbuagbaw L, Mafuta A, Tchana $\mathrm{M}$ and Choukem SP. (2018). Adolescent deliveries in urban Cameroon: a retrospective analysis of the prevalence, 6 year trend and adverse outcomes. BMC Res Notes 13 ;11(1):469

16. Agbor VN, Mbanga CM and Njim T. (2017). Adolescent deliveries in rural Cameroon: an 8 year trend, prevalence and adverse maternofoetal outcomes. Reprod Health 29;14(1):122

17. Kurth F, Belard S, Mombo-Ngoma G, Schuster K, Adegnika AA, Bouyou-Akotet MK, Kremsner PG and Ramharter M. (2010). Adolescent as risk factor for adverse pregnancy outcomes in Central Africa - a cross sectional study. PLoS One 20;5(12):e14367

18. Kassa G, Arawojolu A, Odukogbe A and Yalew A. (2018). Prevalence and determinants of adolescent pregnancy in Africa: A systematic review and Meta-analysis. Reproductive health 15:219

19. Brabin L, Verhoeff FH, Kazembe P, Brabin BJ, Chimsuku L and Broadhead R. (1998). Improving antenatal care for pregnant adolescents in southern Malawi. Acta Obstet Gynecol Scand 77(4):402-9

20. Mataya R. (2016). Report on the Confidential Enquiry into Maternal Deaths in Malawi (2008-2012) CEMD.

21. Dierickx S, Rahbari L, Longman C, Jaiteh F and Coene G. (2018). "I am always crying on the inside": A qualitative study on the implications of infertility on the women's lives in the Gambia. Reproductive health 15, Article number: 151

22. Zeck W, Wilkinson J, Obure J, Masenga G, Ulrich D and Oneko O. (2010). Comparison of obstetrical risk in adolescent primiparas at tertiary referral centres in Tanzania and Austria. J Matern Fetal Neonatal Med 23(12): 1470-4

23. Ali M and Lulseged S. (1997). Factors influencing adolescent birth outcome. Ethiop Med J. Jan ;35(1):35-42 